\title{
Correction to: Modelling effects of an asphalt road at a dike crest on dike cover erosion onset during wave overtopping
}

\author{
A. Bomers ${ }^{1}$ (D) - J. P. Aguilar Lopez ${ }^{1,2}$ - J. J. Warmink ${ }^{1}$ - S. J. M. H. Hulscher ${ }^{1}$ \\ Published online: 31 August 2018 \\ (C) The Author(s) 2018
}

\section{Correction to: Nat Hazards (2018) 93:1-30 \\ https://doi.org/10.1007/s11069-018-3287-y}

The article was published Open Access under the Dutch Compact Agreement; however, due to an internal system error, previous HTML rendering of the article did not reflect this. The original article has been corrected.

The original article can be found online at https://doi.org/10.1007/s11069-018-3287-y.

$\triangle$ A. Bomers

a.bomers@utwente.nl

J. P. Aguilar Lopez

j.p.aguilarlopez@tudelft.nl

J. J. Warmink

j.j.warmink@utwente.nl

S. J. M. H. Hulscher

s.j.m.h.hulscher@utwente.nl

1 Department Water Engineering and Management, University of Twente, Dienstweg 1, 7522 NB Enschede, The Netherlands

2 Present Address: Department Water Management, Delft University of Technology, Delft, The Netherlands 